\title{
Deltamethrin-Incorporated Nets as an Integrated Pest Management Tool for the Invasive Halyomorpha halys (Hemiptera: Pentatomidae)
}

\author{
T. P. Kuhar, ${ }^{1,2}$ B. D. Short, ${ }^{3}$ G. Krawczyk, ${ }^{4}$ and T. C. Leskey ${ }^{3}$ \\ 1Department of Entomology, Virginia Tech, Blacksburg, VA 24061-0319 (tkuhar@vt.edu), ${ }^{2}$ Corresponding author, e-mail: tkuhar@vt.edu, \\ ${ }^{3}$ USDA-ARS, Appalachian Fruit Research Station, Kearneysville, WV 25430-2771 (brent.short@ars.usda.gov; tracy.leskey@ars.usda.gov), \\ and ${ }^{4}$ Fruit Research and Extension Center, Pennsylvania State University, Biglerville, PA 17307-0330 (gxk13@psu.edu)
}

Subject Editor: Joseph Munyaneza

Received 16 November 2016; Editorial decision 20 December 2016

\begin{abstract}
Long-lasting insecticide nets (LLINs), which have insecticide incorporated within the fibers, have been widely used for control of malaria and other insect-vectored diseases. Only recently have researchers begun exploring their use for control of agricultural pests. In this study, we evaluated the toxicity of a deltamethrin-incorporated LLIN, ZeroFly (Vestergaard-Frandsen, Washington, DC) for control of the brown marmorated stink bug, Halyomorpha halys (Stål). In the lab, exposure to the ZeroFly net for 10 s resulted in $>90 \%$ mortality of $H$. halys nymphs and $>40 \%$ mortality of $H$. halys adults. Longer exposure to the net resulted in higher mortality. In another experiment, a $15-\mathrm{cm}^{2}$ sheet of ZeroFly net placed inside of the stink bug trap provided long-lasting kill of $H$. halys adults equal to or better than standard dichlorvos kill strip. Potential for the use of ZeroFly nets for $H$. halys IPM is discussed.
\end{abstract}

Key words: : Halyomorpha halys, long-lasting insecticide net, trap, attract and kill

Insecticide-treated nets have been widely used as a malaria vector control tool around the world since the mid-1990s (Hill et al. 2006). These nets are typically treated with a pyrethroid insecticide, such as permethrin or deltamethrin, which repel, incapacitate, and kill mosquitoes (Diptera: Culicidae) that land on the nets. As an advancement over nets that are dipped in insecticides, and which require retreating after a few washings or a year of use, long-lasting insecticidal nets (LLINs) have been developed with the netting material (usually polyethylene, or polyester) that has insecticide incorporated within or bound around the fibers (Martin et al. 2007, Reimer et al. 2016). With LLINs, insecticide from within the fibers continues to move to the surface over time, replacing the residue that may have been removed by washing; this enables long (multiyear) residual efficacy of the nets (Martin et al. 2007).

Researchers have recently begun exploring the use of LLINs for management of agricultural pests. In particular, pyrethroidincorporated nets applied as floating row covers, or 2-m high fences, have been shown to be efficacious for control of various lepidopteran and aphid pests of vegetables (Martin et al. 2006, Licciardi et al. 2008, Dáder et al. 2015), and are considered to be costeffective because they control multiple key pests, last multiple years, and because larger mesh sizes can be used compared with untreated row covers (Dáder et al. 2015). To our knowledge, the efficacy of LLINs for control of pestiferous stink bugs (Hemiptera: Pentatomidae) has not been investigated.
Herein, we report on the toxicity of a commercially available deltamethrin-incorporated LLIN, ZeroFly screen (VestergaardFrandsen, Washington, DC), on an important invasive pest in the United States and Europe, the brown marmorated stink bug, Halyomorpha halys (Stål) (Hemiptera: Pentatomidae) (Leskey et al. 2012b, Rice et al. 2014), and explore strategies for the use of the ZeroFly nets in stink bug IPM.

\section{Materials and Methods}

\section{Netting}

All experiments were conducted with black ZeroFly netting obtained from Vestergaard-Frandsen (Lausanne, Switzerland) in spring 2015. The netting was supplied as a $15-$ by $1.8-\mathrm{m}$ roll, mesh size of 32-33 holes per $\mathrm{cm}^{2}$, and was incorporated with deltamethin at $\sim 3.85 \mathrm{mg}$ a.i./g fiber. For untreated controls, we used a roll of 7.6- by 1.2-m charcoal fiberglass window screen FCS8480-M (Saint-Gobain ADFORS Clear Advantage); the untreated screen had the same mesh size and color as the ZeroFly screen.

\section{Insects}

Adult $H$. halys were collected from buildings (fall), trees, and agricultural plants during the summer. Nymphs for bioassays were obtained from a colony at Virginia Tech, Blacksburg, VA, maintained 
in a growth chamber at $60-80 \% \mathrm{RH}, 27 \pm 2^{\circ} \mathrm{C}$, with a photoperiod of 16:8 (L:D) h, and provisioned with green beans, Phaseolus vulgaris L., raw shelled peanuts, Arachis hypogaea L., and a water wick.

\section{Residual Efficacy Bioassay}

In summer 2015 and 2016 in Blacksburg, VA, bioassays were conducted on $H$. halys nymphs (third and fourth instars) and in fall 2016, similar bioassays were conducted on adults. For each bioassay, $\sim 10$ insects were placed simultaneously in a 1 -liter plastic container lined with the netting, so that the insects could forage freely, but remained in contact with the netting. Various intervals of exposure were evaluated including $10 \mathrm{~s}, 1 \mathrm{~min}$, and $10 \mathrm{~min}$ on the ZeroFly netting and $1 \mathrm{~min}$ on the untreated screen as a control. Following exposure, the insects were immediately transferred to untreated containers provisioned with a green bean pod and a moistened water wick. Mortality of the bugs was assessed after $24 \mathrm{~h}$. The bioassay was replicated four times each on different dates and with different bugs. Following arc-sine square root transformation, mortality data were analyzed using one-way ANOVA and Fisher's Protected LSD to separate means at the $P<0.05$. All statistical analyses were carried out using JMP Pro 11.0 (SAS 2013). Probit analysis (LeOra Software 2002) was used to calculate $\mathrm{LT}_{90}$ values (lethal exposure time) and $95 \%$ fiducial limits (FL) for both nymphs and adults.

\section{Comparison of Killing Agents in Pheromone} Trap Jar Tops

Experiments were conducted at the Appalachian Fruit Research Station in Kearneysville, WV, in 2016 using Dead-Inn Stink Bug traps (40.6 cm height, AgBio, Inc., Westminster, CO). Each trap top was composed of a plastic jar that was 10.2 by 10.2 by $15.2 \mathrm{~cm}$ (W by $\mathrm{L}$ by $\mathrm{H}$ ), with a funnel that had a 7.6- $\mathrm{cm}$ opening. Inside each jar top, one of the four treatments was evaluated for efficacy and speed of kill of adult $H$. halys: 1) ZeroFly netting, 2) lambdacyhalothrin-treated netting, 3) dichlorvos kill strip, current standard for insect traps (Leskey et al. 2012a), and 4) no killing agent (control). The ZeroFly net was cut into $15-\mathrm{cm}^{2}$ sheets and wrapped tightly around the funnel cone on the inside of the jar and fastened with a paper clip. The lambda-cyhalothrin treated netting was produced by soaking $15-\mathrm{cm}^{2}$ pieces of polyester no-see-um mesh in a $2.3 \%$ a.i. solution of Warrior II with Zeon Technology (Syngenta Crop Protection, Greensboro, NC) for $1 \mathrm{~h}$. The netting was fully dried before being attached to the funnel as the ZeroFly netting. For the dichlorvos kill strip, a half piece of Hercon Vaportape II (Hercon Environmental, Emigsville, PA) was suspended inside the jar by a paper clip. Adults $H$. halys were released individually into one of the aforementioned treatments. Four response variables were assessed: 1) escape from jar, 2) time until escape, 3) mortality in jar, and 4) time until death. Evaluations of $H$. halys presence and condition were taken at 10-15-min intervals for a period of $3 \mathrm{~h}$. Treatment effects on the binomial variables (escape and mortality) were analyzed using logistic regression and then chi-square pairwise comparisons to distinguish among treatments. Treatment effects on the continuous variables (time until escape and death) were analyzed using a t-test and ANOVA with Tukey's HSD test, respectively (JMP 11.0, SAS 2013).

\section{Results and Discussion}

\section{Residual Efficacy Bioassay}

The ZeroFly net was highly toxic to $H$. halys nymphs and adults (Fig. 1). There was an effect of exposure time on the net on mortality of $H$. halys nymphs $(F=534.4 ; \mathrm{df}=3 ; P<0.001)$, with an $\mathrm{LT}_{90}=8.27 \mathrm{~s}(95 \% \mathrm{FL}=0.65-121.11 ;$ slope $=0.783)$. There was also an effect of exposure time on mortality of $H$. halys adults $(F=8.46 ; \mathrm{df}=3 ; P<0.003)$. Adult mortality averaged 40.8, 48.3, and $83.6 \%$ for $10-\mathrm{s}, 1-\mathrm{min}$, and $10-\mathrm{min}$ exposures, respectively, with an $\mathrm{LT}_{90}=39.8 \mathrm{~min}(95 \% \mathrm{FL}=9.30-141.66$; slope $=0.692)$.

\section{Comparison of Killing Agents in Pheromone Jar Tops}

There was an effect of treatment on the percentage of $H$. halys adults that escaped jar tops $\left(\chi^{2}=17.75 ; \mathrm{df}=3 ; \quad P=0.0005\right)$.

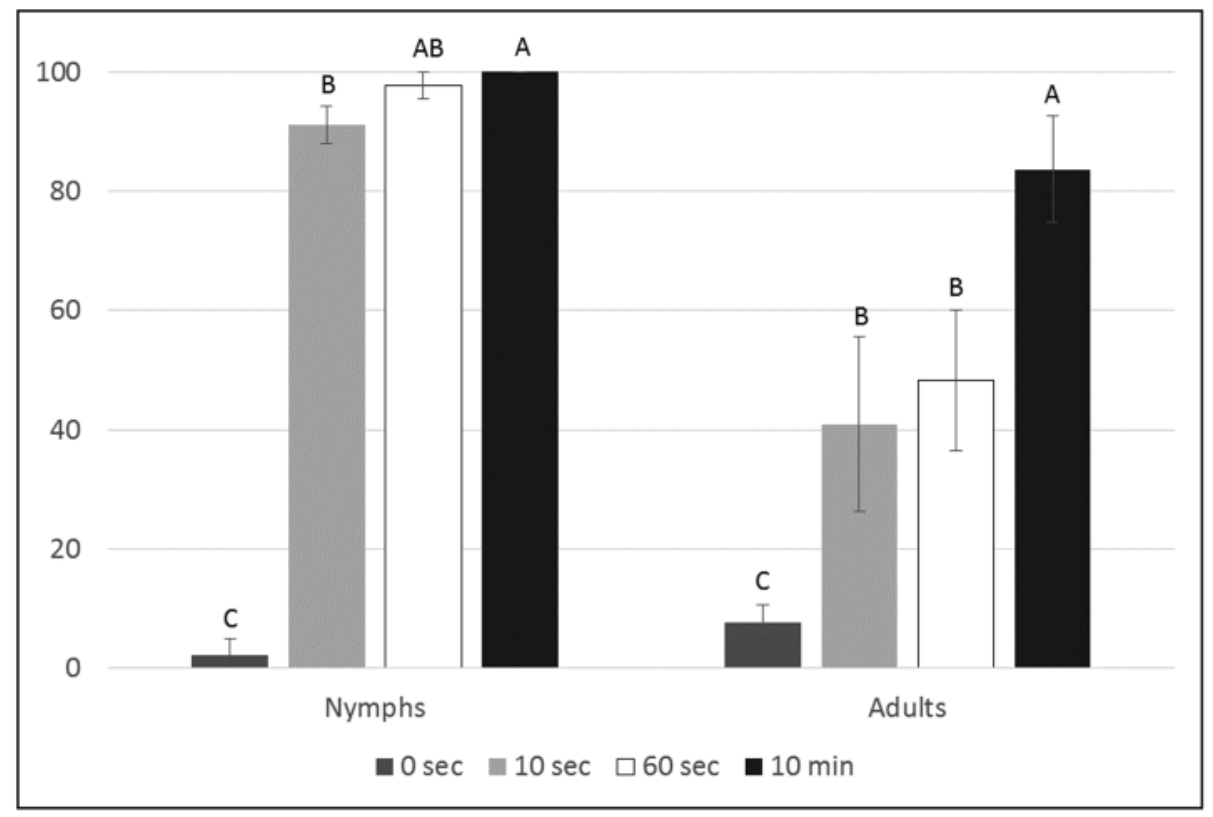

Fig. 1. Percentage mortality (mean \pm SE) of $H$. halys nymphs and adults $24 \mathrm{~h}$ after brief exposure periods to ZeroFly net in the lab. 
Table 1. Percentage and time until escape or death (mean \pm SEM) of $H$. halys adults placed in commercial Dead-Inn stink bug trap jars

\begin{tabular}{lcccc}
\hline Treatment & \multicolumn{3}{c}{ Mean \pm SEM } \\
\cline { 2 - 5 } & \% Escaped $^{a}$ & ${\text { Time until escape }(\min )^{b}}^{b}$ & \% Dead $^{c}$ & ${\text { Time until dead }\left(\mathrm{min}^{d}\right.}^{d}$ \\
\hline Dichlorvos kill strip & $16.67 \pm 7.78 \mathrm{a}$ & $42.75 \pm 10.13 \mathrm{a}$ & $83.33 \pm 7.78 \mathrm{~b}$ & $54.75 \pm 4.65 \mathrm{~b}$ \\
Lambda-cyhalothrin-treated net & $0.00 \pm 0.00 \mathrm{~b}$ & N/A & $100.00 \pm 0.00 \mathrm{a}$ & $61.17 \pm 4.27 \mathrm{~b}$ \\
ZeroFly net & $0.00 \pm 0.00 \mathrm{~b}$ & N/A & $88.00 \pm 6.63 \mathrm{ab}$ & $76.59 \pm 4.83 \mathrm{a}$ \\
Control & $29.17 \pm 9.48 \mathrm{a}$ & $44.14 \pm 12.60 \mathrm{a}$ & $4.17 \pm 4.17 \mathrm{c}$ & $45.00 \pm 0.00$ \\
\hline
\end{tabular}

${ }^{a}$ Hercon Vaportape II $(N=24)$; Lambda-cyhalothrin Netting $(N=23)$; ZeroFly Netting $(N=25)$; Control $(N=24)$.

${ }^{b}$ Hercon Vaportape II $(N=4)$; Control $(N=7)$.

${ }^{c}$ Hercon Vaportape II $(N=20)$; Lambda-cyhalothrin Netting $(N=23)$; ZeroFly Netting $(N=25)$; Control $(N=24)$.

${ }^{d}$ Hercon Vaportape II $(N=20)$; Lambda-cyhalothrin Netting $(N=23)$; ZeroFly Netting $(N=22)$. Control excluded from analysis due to a rep of 1.

Halyomorpha halys adults escaped only from untreated control jar tops and those containing dichlorvos, but there was no difference in the percentage of $\left(\chi^{2}=1.07 ; \mathrm{df}=1 ; P=0.3005\right)$ or time until escape $(\mathrm{t}=0.09 ; \mathrm{df}=8.86 ; P=0.9332)$ between these two treatments. There was an effect of treatment on the percentage of dead $H$. halys adults $\left(\chi^{2}=70.96 ; \mathrm{df}=3 ; P<0.0001\right)$ and the time until death $(F=5.90 ; \mathrm{df}=2,62 ; P=0.0045)$. All jars provisioned with killing agents resulted in significant mortality of adults compared with the untreated control, with the highest rates, $100 \%$ and $88 \%$, recorded from the lambda-cyhalothrin-treated and ZeroFly netting, respectively (Table 1).

Our experiments showed ZeroFly nets are quite toxic to $H$. halys, delivering a lethal dose of deltamethrin to bugs within several seconds or minutes of exposure depending on stage of the bug. We also showed a small square of the net can be used effectively as a killing agent in traps replacing dichlorvos. Additional research on other uses of the ZeroFly net for $H$. halys IPM is ongoing. In particular, the use of nets in combination with aggregation pheromone lures (Weber et al. 2014) has shown promise as an attract-and-kill device (TPK and GK, unpublished data). ZeroFly nets and other LLINs show tremendous potential for use in pest management of $H$. halys and many other insects as well.

\section{Acknowledgments}

We would like to thank McKenzie Allen for technical assistance with the laboratory testing at AFRS. Funding for this research was provided in part by 2016-04959 2016-51181-25409 grant award. The ZeroFly netting used in these experiments was provided by Georgina Bingham, VestergaardFrandsen, Washington, DC.

\section{References Cited}

Dáder, B., S. Legarrea, A. Moreno, M. Plaza, M. Carmo-Sousa, F. Amor, E. Viñuela, and A. Fereres. 2015. Control of insect vectors and plant viruses in protected crops by novel pyrethroid treated screens. Pest Manag. Sci. 71: 1397-1406.

Hill, J., J. Lines, and M. Rowland. 2006. Insecticide-treated nets. Adv. Parasitol. 61: 77-128.

LeOra Software. 2002. Polo plus: Probit and logit analysis. Version 1.0. LeOra Software, Berkeley, CA.

Leskey, T. C., S. E. Wright, B. D. Short, and A. Khrimian. 2012a. Development of behaviorally-based monitoring tools for the brown marmorated stink Bug (Heteroptera: Pentatomidae) in commercial tree fruit orchards. J. Entomol. Sci. 47: 76-85.

Leskey, T. C., B. D. Short, B. R. Butler, and S. E. Wright. 2012b. Impact of the invasive brown marmorated stink bug, Halyomorpha halys (Stål), in mid-Atlantic tree fruit orchards in the United States: Case studies of commercial management. Psyche doi:10.1155/2012/535062.

Licciardi, S., F. Assogba-Komlan, I. Sidick, F. Chandre, J. M. Hougard, and T. Martin. 2008. A temporary tunnel screen as an eco-friendly method for small-scale farmers to protect cabbage crops in Benin. Int. J. Trop. Ins. Sci. 27: 152-158.

Martin, T., F. Assogba-Komlan, T. Houndete, J. M. Hougard, and F. Chandre. 2006. Efficacy of mosquito netting for sustainable small holders' cabbage production in Africa. J. Econ. Entomol. 99: 450-454.

Martin, T., F. Chandre, J. Chabi, P. F. Guillet, M. Akogbeto, and J. M. Hougard. 2007. A biological test to quantify pyrethroid in impregnated nets. Trop. Med. Int. Health 12: 245-250.

Reimer, L. J., E. K. Thomsen, G. Koimbu, J. B. Keven, I. Mueller, P. M. Siba, J. W. Kazura, M. W. Hetzel, and P. A. Zimmerman. 2016. Malaria transmission dynamics surrounding the first nationwide long-lasting insecticidal net distribution in Papua New Guinea. Malar. J. 15: 25. doi:10.1186/ s12936-015-1067-7.

Rice, K. B., C. J. Bergh, E. J. Bergmann, D. J. Biddinger, C. Dieckhoff, G. Dively, H. Fraser, T. Gariepy, G. Hamilton, T. Haye, et al. 2014. Biology, ecology, and management of brown marmorated stink bug (Hemiptera: Pentatomidae). J. Integr. Pest Manag. 5: 1-13.

Weber, D. C., T. C. Leskey, G. C. Walsh, and A. Khrimian. 2014. Synergy of aggregation pheromone with methyl (E,E,Z)-2,4,6-decatrienoate in attraction of Halyomorpha halys (Hemiptera: Pentatomidae). J. Econ. Entomol. 107: 1061-1068. 